\title{
Thrombosis of Isolated Ductus Arteriosus Aneurysm In A Newborn
}

\author{
Vehbi Dogan ${ }^{1}$, Ömer Aksoy ${ }^{1}$, İlker Sayıc1 ${ }^{1}$, and Rümeysa Citli ${ }^{1}$ \\ ${ }^{1}$ SBU Ankara Dr Sami Ulus Maternity Child Health and Diseases Training and Research \\ Hospital
}

January 11, 2021

\begin{abstract}
Congenital aneurysm of the ductus arteriosus is reported in $0.8 \%$ in neonatal autopsies, however true incidence is unknown because of high rate of asymptomatic cases and spontaneous regression. Possible complications in symptomatic cases are; thromboembolism, spontaneous rupture, erosion, infection, compression of airways and death. In this report we present a newborn with giant DAA diagnosed in first day of life, surgically treated after thrombosis of aneurysm.
\end{abstract}

\section{Thrombosis of Isolated Ductus Arteriosus Aneurysm In A Newborn}

Doğan Vehbi ${ }^{1}$, Aksoy ÖN² ${ }^{2}$ Sayıcı İU ${ }^{1}$, Çitli $\mathrm{R}^{3}$.

${ }^{1}$ Dr. Sami Ulus Maternity and Children's Health and Diseases Training and Research Hospital, Department of Pediatric Cardiology, Ankara, Turkey.

${ }^{2}$ Dr. Sami Ulus Maternity and Children's Health and Diseases Training and Research Hospital, Department of Pediatric Cardiovascular Surgery, Ankara, Turkey.

${ }^{3}$ Dr. Sami Ulus Maternity and Children's Health and Diseases Training and Research Hospital, Department of Neonatology, Ankara, Turkey.

Corresponding author

Name : Vehbi Doğan

Orcid ID : 0000-0003-3444-3419

e-mail : vdogan86@yahoo.com

Adress : Dr.Sami Ulus Maternity and Children Research and Training

Hospital, Babur Street, No:44 (06080) Altındağ/ Ankara, Turkey

Fax : +903123170353

Phone : +90 5053190186a

\section{Abstract}

Congenital aneurysm of the ductus arteriosus is reported in $0.8 \%$ in neonatal autopsies, however true incidence is unknown because of high rate of asymptomatic cases and spontaneous regression. Possible complications in symptomatic cases are; thromboembolism, spontaneous rupture, erosion, infection, compression 
of airways and death. In this report we present a newborn with giant DAA diagnosed in first day of life, surgically treated after thrombosis of aneurysm.

Keywords: ductus arteriosus, aneurysm, thrombosis, newborn

\section{Case Report}

A male newborn with a gestational age of $38 \mathrm{w}$ and birth weight of $2900 \mathrm{~g}$ was consulted to our clinic because of murmur and $5 \%$ difference in pulse oximetry screening test in first day of life. Physical examination was normal except $2 / 6$ cardiac murmur. Echocardiography revealed a small sized apical muscular ventricular septal defect and ductal patency with a large ductal aneurysm, narrowed pulmonary end with left to right shunt and swirling motion in the aneurysm (Fig.1a and 1b, Video 1 and 2). The patient was asymptomatic, therefore we decided for clinical follow up without medication. On the third day of life, echocardiography revealed closed pulmonary end of the ductus and presence of trombus in the aneurysm extending towards decscending aorta (Fig. 1c and Video 3). Surgical resection of ductal aneurysm was enrolled because of risk of embolism (Fig. 1d). Post-operative echocardiography showed residual thrombosis in the aortic side, which fully disappeared on the second week of life with low molecular weight heparin treatment.

\section{Discussion}

Although being mostly asymptomatic, aneurysm of the ductus arteriosus (DAA) can lead to severe complications in some cases. It is reported in less than $1 \%$ of neonatal autopsies, whereas Jan et al. reported relatively high incidence rate of $8.8 \%$ without any symptomatic case, probably because of the diagnostic criteria they used $[1,2]$. DAA related symptoms as thromboembolism, spontaneous rupture, compression of airways and nerves and even death are reported in up to $16-30 \%$ of patients [3-6].

Etiology of DAA is unknown, however hypothesis as abnormal elastin expression or structure, ductal wall weakening and reduced intimal cushions are reported in some studies. Associated connective tissue diseases (Marfan syndrome, Ehler Danlos syndrome etc.) with DAA supports the hypothesis of ductal wall abnormality $[2,3]$.

Most cases are asymptomatic and regress spontaneously and should be managed with clinical follow up. Jan et al. reported that all of the cases regressed spontaneously in the neonatal period and suggested no intervention [2]. However, in case of complications such as extending thrombosis, laryngeal nerve or airway obstruction and rupture of aneurysm, surgical intervention should be considered. Spontaneous regression occurs in steps as constriction, thickening, trombus formation and closure. Although thrombosis is a step in natural history during spontaneous closure, large aneurysm and extension of the thrombus into the descending aorta indicated surgical excision of the aneurysm in our case. In some cases, especially in patients with nerve palsy, ligation and decompression of the aneurysm instead of excision is also suggested.

In our patient thrombosis developed in third day of life during expectation of spontaneous closure. Clinical follow up for the possible symptoms and serial echocardiography should be enrolled to identify the need for intervention in patients with DAA.

\section{Conflict of Interest}

None declared.

\section{Funding}

None.

\section{References}

1. Falcone MW, Perloff JK, Roberts WC. Aneurysm of the nonpatent ductus arteriosus. Am J Cardiol 1972;29:422-426.

2. Jan SL, Hwang B, Fu YC, Chai JW, Chi CS. Isolated neonatal ductus arteriosus aneurysm. J Am Coll Cardiol. 2002;39:342-347. 
3. Lund JT, Hansen D, Brocks V, Jensen MB, Jacobsen JR. Aneurysm of the ductus arteriosus in the Neonate: Three case reports with a review of the literature. Pediatr Cardiol. 1992;13:222-226.

4. Dyamenahalli U, Smallhorn JF, Geva T, Fouron JC, Cairns P, Jutras L, Hughes V, Rabinovitch M, Mason C AE, Hornberger LK. Isolated ductus arteriosus aneurysm in the fetus and infant: a multi institutional experience. J Am Coll Cardiol 2000;36:262-269.

5. Hornung TS, Nicholson IA, Nunn GR, Hawker RE. Neonatal ductus arteriosus aneurysm causing nerve palsies and airway compression: Surgical treatment by decompression without excision. Pediatr Cardiol. 1999;20:158-160

6. Koneti NR, Kanchi V, Kandraju H, Jaishankar S. Symptomatic aneurysm of ductus arteriosus in neonates Ann Pediatr Cardiol. 2011;4:159-163.
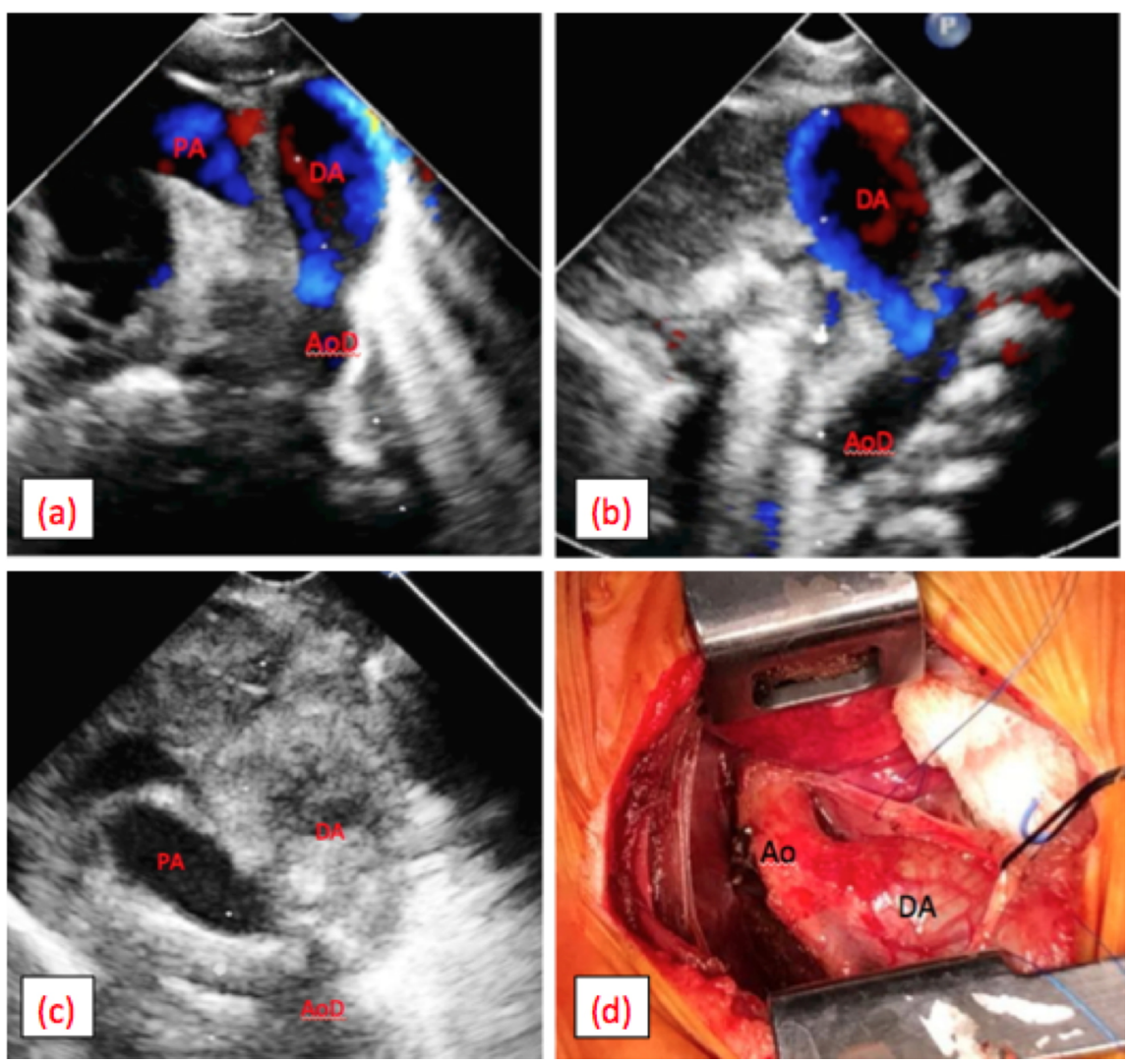